\title{
The influence of the moisture weight ratio and the activity of the invertase enzyme on the crystallization rate of natural honey
}

\author{
E. A. Murashova ${ }^{1, *}$, O. A. Karelina ${ }^{1}$, and $O . V$. Serebryakova ${ }^{2}$ \\ ${ }^{1}$ Ryazan State Agrotechnological University Named after P. A. Kostychev, 390048, Ryazan, Russian \\ Federation \\ ${ }^{2}$ Federal Scientific Center of Beekeeping, 22, Pochtovaya Str., Rybnoe, 391110, Russian Federation
}

\begin{abstract}
The article presents studies on the dependence of the crystallization rate of natural honey on the moisture weight ratio, the activity of the invertase enzyme. Based on the results presented, preliminary conclusions can be drawn, which indicate that the higher the activity of the invertase enzyme, the sooner the crystallization of the honey begins.
\end{abstract}

\section{Introduction}

The consistency of honey is an important property of its appearance, which is assessed when determining its organoleptic characteristics in accordance with regulatory documents. Consistency includes a complex of rheological properties of natural honey. These properties are interdependent on each other. These include crystallization, viscosity, thixotropy, surface tension, cohesion, adhesion, and so on. In relation to honey, the term "consistency" is used to describe its structure. That is why an important point in describing the consistency of natural honey is describing the nature of its crystallization $[1,2]$.

Crystallization or granulation of natural honey is a natural transition from a viscous, liquid state to a crystalline one, without changing the composition and basic physical and chemical properties. One of the main reasons for crystallization is that honey is an unstable supersaturated solution of sugars, which, when crystallized, passes into a more chemically stable state. At the same time, the monosaccharide glucose (melicitose in honeydew honey) precipitates into crystals, and fructose, in turn, is a more soluble carbohydrate, and therefore crystallizes more slowly. The latter encases glucose crystals or accumulates on the surface of honey, forming a dark layer of viscous sweet liquid. The crystallization process stops when honey ceases to be a supersaturated solution $[3,4,5]$.

It is known that the carbohydrate spectrum of natural mature honey is represented mainly by two monosaccharides: glucose and fructose, which are also called reducing sugars. Honey, which is formed from flower nectar, contains about $65-80 \%$ of reducing sugars and honeydew honey has about 50-65 \%. Reducing sugars in honey have their origin from initial substances and sucrose contained in honey. Sucrose in turn enters the honey

* Corresponding author: murashova.36@mail.ru 
from the nectar and salivary glands of bees under the action of the invertase enzyme. Helmut Horn found that in percentage terms, fructose predominates in reducing sugars and its amount ranges from 34 to $41 \%$, while the glucose content ranges from 28 to $35 \%$. It is this ratio that is the main reason for honey crystallization. The study of the value of this ratio makes it possible to estimate and predict in advance the intensity of the crystallization process of honey [6].

If honey is mainly rich in fructose, then the process of crystallization is slow and the honey mass will tend to soften and exfoliate. As it has already been mentioned, glucose crystals deposit, and a dark liquid rich in fructose forms on the top. It should be noted that such honey is not easy to sell, as it loses its appearance for the consumer [7, 8].

It is known that the process of honey crystallization begins with the formation of primitive crystals. They are microscopic particles of glucose, pollen grains, which are the centers on which new crystals grow. They are formed primarily at the walls and bottom of the container, and grow, turning into larger structures, uniting with each other. When there are few or no primitive crystals, the centers are glucose molecules in a specific order. These primary glucose crystals are formed at an optimum temperature of $7-15^{\circ} \mathrm{C}$. In the case when granulation begins with uneven primitive crystals and passes under unregulated conditions. A coarse crystal structure is obtained, which is felt like sand on the tongue and is not liked by the consumer. The beginning of crystallization from uniform small primitive crystals is the most acceptable one. It takes place under balanced microclimatic conditions. The crystal structure of such honey is creamy or fat-like $[9,10]$.

A microscope is used to determine the presence of large or small crystals in honey. A drop of honey is applied to a glass slide and examined under $40 \times$ magnification (Fig. 1, 2).

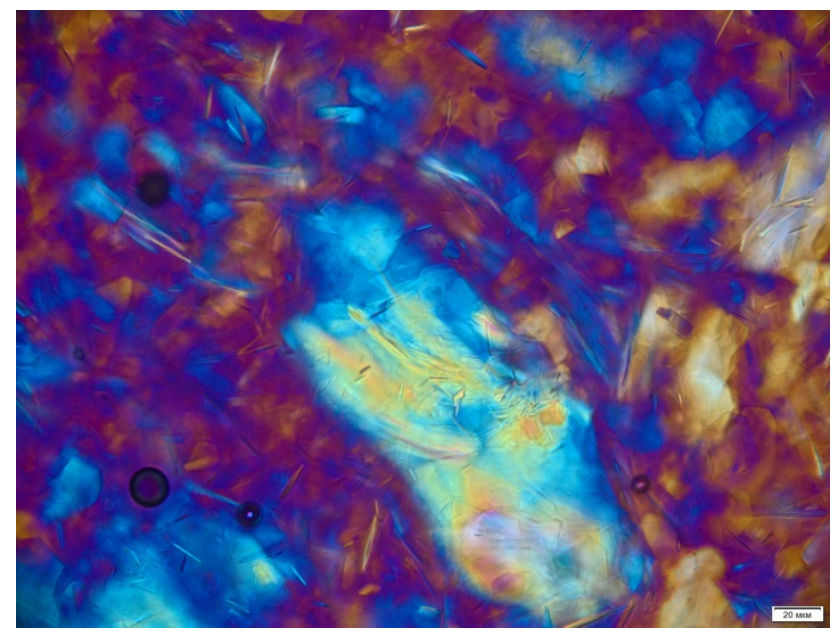

Fig. 1. Large nucleated crystal structure, at $40 \times$ magnification (polarized microscope Olimpus CX56). 


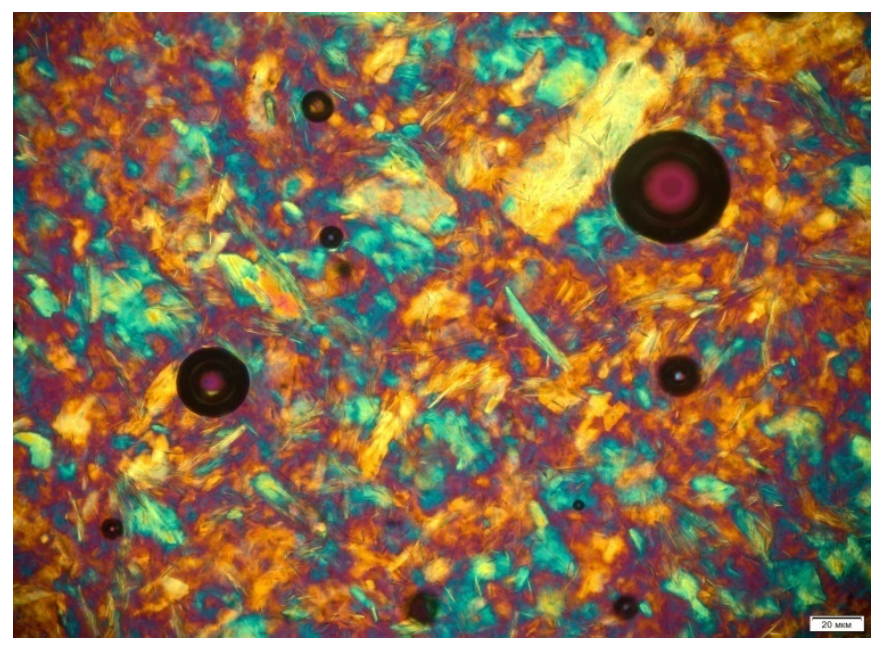

Fig. 2. Fine nucleated crystal structure, at $40 \times$ magnification (polarized microscope Olimpus CX56).

It should be noted that glucose in aqueous solution is in two forms: a-glucose and $\beta$ glucose, which exhibit different properties. If a-glucose crystallizes into monocyclic conglomerates with the formation of crystalline hydrate and with a decrease of water in honey (that is, there is one molecule of water per glucose molecule in the crystal lattice), then $\beta$-glucose is better soluble in water, therefore, with rapid crystallization there is an increased content of $\beta$-glucose in the upper layers of honey. The crystallization process itself usually begins at the border of the aggregates: liquid - solid, or liquid - air. Fluctuations in air temperature contribute to the release or reception of water from the air, since honey is very hygroscopic. As a result, areas oversaturated with glucose are formed in the surface layer of the honey mass and contribute to the more rapid formation of crystallization centers [11].

The density of glucose crystals is 1.54 , and the density of honey is from 1.45 to 1.4 . Therefore, crystals formed in such honey can be on the edge of the phases, that is, crystallization goes from top to bottom. If the density of honey is lower, then the nucleated crystals go down and grow larger during storage.

When honey is completely crystallized, the intercrystalline liquid, which contains fructose, free water and soluble substances, encases glucose crystals. If the glucose content is relatively high, then the entire intercrystalline liquid is not enough to cover all the glucose, so some of the crystals accumulate on the surface of the honey mass in the form of a light loose layer. This layer is less sweet, because fructose is many times sweeter than glucose. Since in the upper layer the formation of these glucose crystals occurs under dehydrated conditions, the $\beta$-glucose form is predominantly formed $[12,13,14]$.

The storage time of honey influences the process of crystallization in the following way. Honey maturation during storage contributes to a gradual decrease in the amount of glucose, which increases with increasing temperature. As a result, the ratio of glucose and fructose changes in favor of the latter, and this prevents further crystallization.

The crystallization process is also influenced by other endogenous factors, such as the ratio of pure glucose to water. If this ratio is $1: 7$, then honey will most likely remain liquid, and with a ratio of 2:1 it will certainly crystallize quickly. So honey weight ratio of water up to $18 \%$ shows a pronounced tendency to crystallization. It crystallizes slowly and not intensively due to the lower sugar concentration. It should also be noted that honey with a moisture content of up to $15 \%$ also crystallizes more slowly, due to its high viscosity, but 
when crystallized, it becomes hard like a stone.

In the process of storing honey, it is necessary to pay special attention to microclimatic parameters and other exogenous factors that affect the nature and course of crystallization.

It should be noted that honey crystallization occurs at different times and depends mainly on its botanical origin. It was found that monofloral honey has a general tendency to crystallize under different conditions of production, processing and storage. Table 1 shows characteristic features of the crystallization process of the most common honey of various botanical origin.

Table 1. The rate and nature of crystallization of different monofloral honey

\begin{tabular}{|l|c|c|c|}
\hline No & $\begin{array}{c}\text { Name of monofloral } \\
\text { honey }\end{array}$ & $\begin{array}{c}\text { Crystallization rate } \\
\text { (months, weeks) }\end{array}$ & Crystallization structure \\
\hline 1 & Sunflower & from 2 weeks to 1 month & coarse granular \\
\hline 2 & Acacia & from 12 to 29 months & fine-granular \\
\hline 3 & White & from 1 to 2.5 months & $\begin{array}{c}\text { medium granular, } \\
\text { fine-granular }\end{array}$ \\
\hline 4 & Clover & from 1 to 2 months & fatty \\
\hline 5 & Cotton & up to 2 months & coarse granular \\
\hline 6 & Cypress & up to 1.5 months & fine-granular, fatty \\
\hline 7 & Sweet clover & up to 3 months & $\begin{array}{c}\text { coarse granular, fine- } \\
\text { granular }\end{array}$ \\
\hline 8 & Buckwheat & from 2 to 4 months & $\begin{array}{c}\text { coarse granular, fine- } \\
\text { granular }\end{array}$ \\
\hline 9 & Ericaceae & becomes hard without & crystallizing \\
\hline 10 & Esparcet & up to 2 months & fine-granular, fatty \\
\hline
\end{tabular}

Table 1 shows that crystallization of honey from different plants has different rate and character. These features of each type and variety of honey are considered when assessing its organoleptic properties in accordance with the established regulatory documentation. This assessment is due to the sensory physiology of the tasting. This phenomenon of somesthesia makes it possible to assess the texture of honey in the intraoral cavity, which is carried out through the mechanoreceptors of the oral mucosa. Thus, the fat content, the hardness of the honey mass, or the type of granulation of the crystal structure are evaluated.

Tactile sensations with their sensing are translated into a specific language. For sensory evaluation, a description is used not only of gustatory and tactile sensations, but also the appearance of the crystallized mass. Among other indicators, purity, transparency, fluidity, color, uniformity and crystallization are evaluated.

Crystallization is one of the main criteria for sensory analysis of honey. When evaluating it, the full dimension, texture and size of crystals are described. The color is determined using a spectrometer equipped with discs for light and dark honey. Each color has a reference to the Pfund scale (color norm for honey). At the end of the description of such a phenomenon as honey crystallization, it should be emphasized once again that it is a natural process. Crystallization of honey does not change its composition and does not contribute to a decrease in taste and quality. However, methods for preventing and slowing down crystallization are most often used only in order to please the consumer with a marketable product, and when necessary for production [15]. Since crystallization is an important process during the storage of honey, the aim of the study was to determine the degree of influence of the main and additional factors on the rate and nature of crystallization of natural honey. Based on the aim, the following objectives were set: 
1) To replenish the database on the influence of the weight ratio of honey moisture on the rate of its crystallization;

2) To analyze the dependence of the crystallization rate on the level of monofloral character;

3) To reveal the effect of invertase enzyme activity on the rate of honey crystallization.

\section{Materials and methods}

The research was carried out in the laboratory of the Federal State Budgetary Scientific Institution "Federal Research Center of Beekeeping". The weight ratio of moisture was determined in selected honey samples according to GOST 31774-2012 Honey. Refractometric method to determine water. The activity of the honey invertase enzyme was determined according to GOST 34232-2017 Honey. Methods for determining the activity of sucrase, diastase number, insoluble substances. The botanical origin of the studied honey samples was determined according to GOST 31766-2012 Monofloral honey. Technical conditions.

\section{Investigation of the influence of the weight ratio of moisture and the activity of the invertase enzyme on the crystallization rate of natural honey}

The results of determining the effect of the weight ratio of moisture on the crystallization rate are shown in Figure 3.

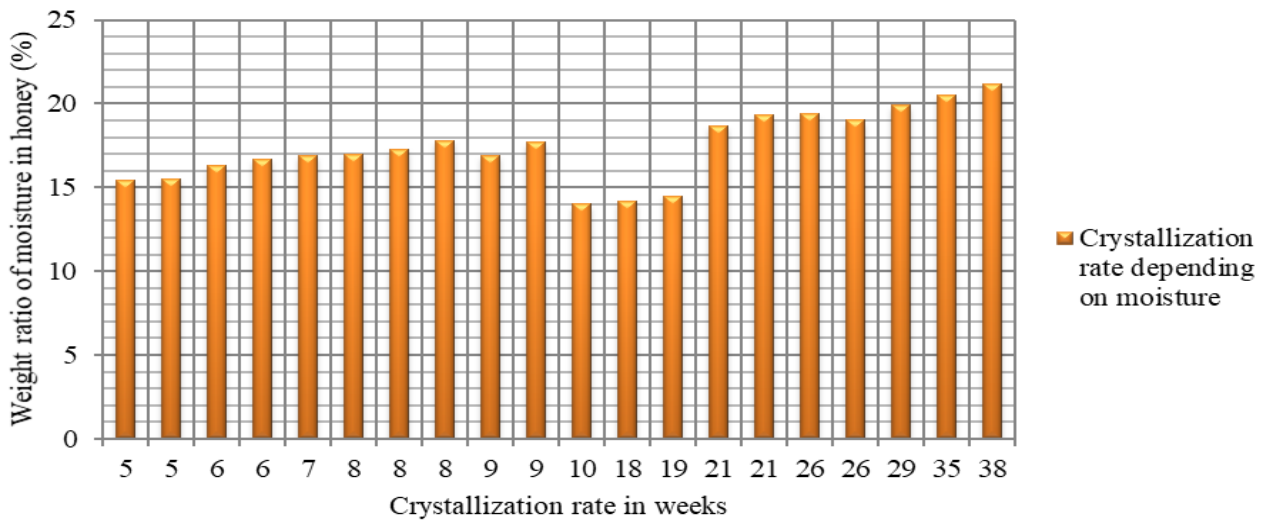

Figure 3-Diagram of the dependence of the crystallization rate on the moisture content of natural honey

Based on the diagram, one can conclude that the moisture content of honey directly affects the rate of its crystallization. Honey with a moisture content of 15.0 to $17.7 \%$ crystallize in an average of 7.5 weeks. Honey with a moisture content of $18.0 \%$ and higher crystallizes slowly, on average for 28 weeks. It should also be noted that honey with a moisture content of up to $15.0 \%$ also crystallizes slowly, on average for 15.5 weeks. This is because honey with low moisture content has high viscosity.

The results of the study of the rate of crystallization of honey depending on the degree of monofloral character of natural honey are presented in Table 2. 
Table 2. The crystallization rate of honey depending on the degree of monofloral character

\begin{tabular}{|c|c|c|c|c|}
\hline Name of honey & Sample & $\begin{array}{c}\text { Pollen grain } \\
\text { content \%, } \\
(\mathrm{M} \pm \mathrm{m})\end{array}$ & $\begin{array}{c}\text { Crystallization } \\
\text { rate (weeks) }\end{array}$ & $\begin{array}{c}\text { Crystallization } \\
\text { structure }\end{array}$ \\
\hline \multirow{3}{*}{ Sunflower } & 1 & $46 \pm 0.03$ & 6 & среднезернистая \\
\cline { 2 - 5 } & 2 & $57 \pm 0.12$ & 4 & coarse granular \\
\cline { 2 - 5 } & 3 & $69 \pm 0.09$ & 3 & coarse granular \\
\hline \multirow{3}{*}{ Buckwheat } & 1 & $34 \pm 0.07$ & 11 & fine-granular \\
\cline { 2 - 5 } & 2 & $57 \pm 0.12$ & 9 & medium granular \\
\cline { 2 - 5 } & 3 & $63 \pm 0.09$ & 8 & medium granular \\
\hline \multirow{3}{*}{ White } & 1 & $32 \pm 0.33$ & 12 & fine-granular \\
\cline { 2 - 5 } & 2 & $49 \pm 0.12$ & 11 & fine-granular \\
\cline { 2 - 5 } & 3 & $58 \pm 0.24$ & 11 & fatty \\
\hline
\end{tabular}

Based on the data obtained, it can be concluded that the crystallization rate of honey depends on its botanical origin. The studied samples of sunflower honey with varying degrees of monofloral character crystallized on average for $4.3 \pm 0.88$ weeks. Samples of honey from buckwheat crystallized for $9.3 \pm 0.88$ weeks. White honey crystallized on average for $11.3 \pm 0.33$ weeks. It is important to note the fact that the rate of crystallization depends precisely on the degree of monofloral character of honey. So honey with a lower content of pollen grains of one honey plant crystallizes several times slower than honey with predominantly one type of pollen grains. The most characteristic structure and crystallization rate were observed for honey with the highest content of pollen grains of monofloral melliferous plants.

The results of studying the effect of the activity of the invertase enzyme on the rate of honey crystallization are shown in the Figure 4.

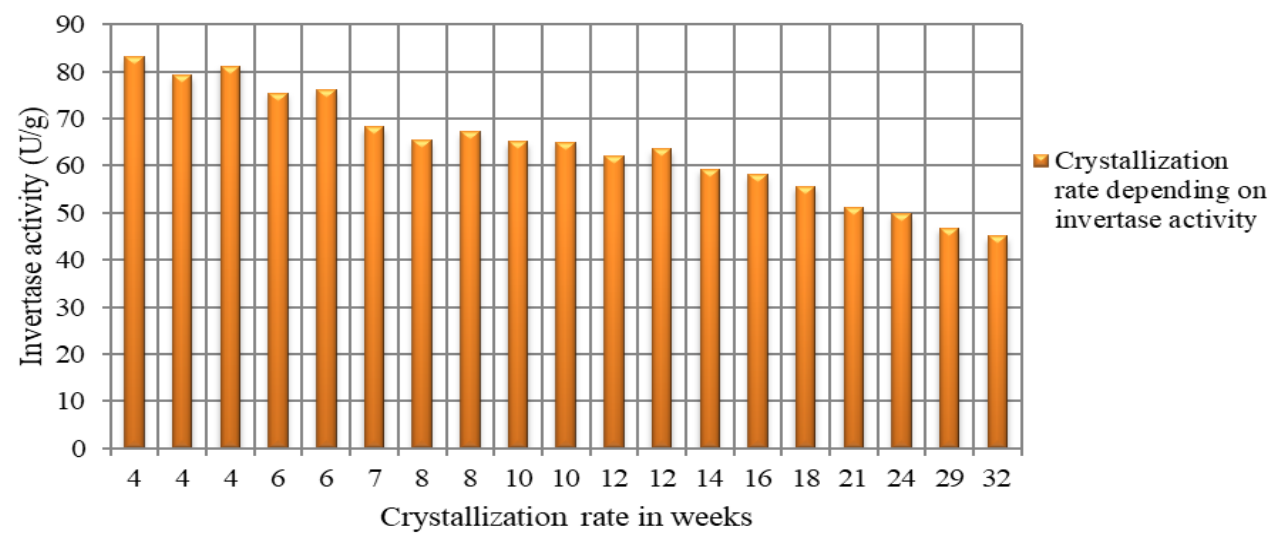

Figure 4-Crystallization rate depending on the activity of the invertase enzyme

The diagram in Figure 4 shows the dependence of the crystallization rate of natural honey on the value of the invertase enzyme activity in its composition. Based on the results presented, preliminary conclusions can be drawn, which indicate that the rate of honey crystallization is directly proportional to the activity of the invertase enzyme. In other words, the higher the activity of the invertase enzyme is, the sooner the honey mass crystallizes.

It is likely that with a high activity of this enzyme, reducing sugars are more likely to 
form, namely glucose, the molecules of which are the centers of crystallization. As a result honey passes into a crystallized state faster.

\section{Conclusion}

Based on the studies carried out and the results obtained, the following conclusions can be drawn.

Honey with a moisture content of 15.0 to $17.7 \%$ crystallizes on average for 7.5 weeks. Honey with a moisture content of $18.0 \%$ and above crystallizes on average for 28 weeks. Honey with a moisture content of up to $15.0 \%$ crystallizes on average for 15.5 weeks.

The studied samples of sunflower honey with varying degrees of monofloral character crystallized on average for $4.3 \pm 0.88$ weeks. Samples of honey from buckwheat crystallized for $9.3 \pm 0.88$ weeks. White honey crystallized on average for $11.3 \pm 0.33$ weeks. Honey with a lower content of pollen grains of one honey plant crystallized several times slower than honey with predominantly one type of pollen grains. The most characteristic structure and crystallization rate were observed for honey with the highest content of pollen grains of monofloral melliferous plants.

Based on the results presented, preliminary conclusions can be drawn, which indicate that the higher the activity of the invertase enzyme is, the sooner the crystallization of the honey mass begins.

The results obtained supplement the database on the degree of influence of the main factors on the rate and nature of crystallization of natural honey.

\section{References}

1. Bogdanov S The Wonders of the Bee Hexagon: The Bee Products Bee Product Science (2017)

2. Dimou M and Thrasyvoulou A A Comparison of three methods for assessing the relative abundance of pollen resources collected by honey bee colonies J. Apicultural Research 46 144-148 (2007)

3. Orczykowska M, Olejnik T P, Rosicka-Kaczmarek J, Miśkiewicz K, Kowalska G Use of phenomenological rheology methods to analyze the viscoelastic properties of bee honeys J. of Food Process Engineering 44(3) 136-137 (2021)

4. Murashova E A, Tunikov G M, Nefedova S A, Karelina O A, Byshova N G, Serebryakova O V Major factors determining accumulation of toxic elements by bees and honey products J. International Transaction Journal of Engineering, Management, \& Applied Sciences \& Technologies 11(3) ID: 11A03 (2020)

5. Brown E, O'Brien M, Georges K, Suepaul S Physical characteristics and antimicrobial properties of Apis mellifera, Frieseomelitta nigra and Melipona favosa bee honeys from apiaries in Trinidad and Tobago BMC complementary medicine and therapies 20(1) 8591 (2020)

6. Byshov N V, Borychev S N, Bakulina G N, Fedoskin V V, Fedoskina I V, Pikushina M $\mathrm{Y}$ Systems analysis when evaluating and forecasting of agricultural enterprises J. Religación. revista de ciencias sociales y humanidades 4(18) 390-404 (2019)

7. Kashirin D E, Uspensky I A, Kostenko M Y, Rembalovich G K , Danilov K I , Kokorev G D,. Byshov D N , Makarov V A, Nefedov B A,Tsymbal A A, Ulyanov V M Cyclic convective drying of bee pollen J. ARPN Journal of Engineering and Applied Sciences 14(4) 916-920 (2019) 
8. Ma Y, Zhang B, Li H, Wang H, Deng Z Chemical and molecular dynamics analysis of crystallization properties of honey International J. of Food Properties 20(4) 725-733 (2017)

9. Kowalski S, Lukasiewicz M Diastase and Invertase Activity Changes and 5Hydroxymethyl-2-Furfural Formation in Honeys Under Influence of Microwave Irradiation J. of Food Process Engineering 40(2) 12410 (2017)

10. Ushakov R N, Ruchkina A V, Levin V I, Zakharova O A, Kostin Ya V, Golovina N A Sustainability of Agro-Gray Soil to Pollution and Acidification, and its Biodiagnostics J. International Journal of Engineering and Technology 7(4.36) 929-934 (2018)

11. Vinogradov,D.V., Vysotskaya, E.A., Naumtseva, K.V., Lupova, E.I. (2020)Features of using modern multicomponent liquid fertilizers in white mustard agrocoenosis J. IOP Conference Series: Earth and Environmental Science 422(1) 012014

12. Drivelos S A, Danezis G P, Halagarda M, Popek S, Georgiou C A Geographical origin and botanical type honey authentication through elemental metabolomics via chemometrics J. Food Chemistry 338127936 (2021)

13. Braghini F, Biluca F C, Gonzaga L V, Costa A C O, Fett R Effect thermal processing in the honey of Tetragonisca angustula: profile physicochemical, individual phenolic compounds and antioxidant capacity J. of Apicultural Research 60(2) 290-296 (2021)

14. Amariei S, Norocel L, Scripcă L A An innovative method for preventing honey crystallization J. Innovative Food Science and Emerging Technologies 66 402-481 (2020)

15. Serebryakova O V, Rusakova T M Improvements in monofloral honey quality control IOP Conference Series: Earth and Environmental Science 624(1) 012149 (2021) 